W.D.R. Writer MB CH B FFARCS FRCP(C), David M. Dewan MD, Francis M. James III MD

\title{
Three per cent 2-chloroprocaine for Caesarean section: appraisal of a standardized dose technique
}

We evainated 2-chloroprocaine, three per cent, in 44 women havirg epidural anaesthesia for Caesarean section. All subjects received a minimum dose of $25 \mathrm{ml} / 750$ $\mathrm{mg}$ ) in increments designed to allow early recognition of accidental subarachnoid or intravascular injection. Further increments were given as needed to achieve a T5 sensory level or higher. We recorded pulse and blood pressure at rwo-minute intervals and used a simple pain scale to assess analgesia.

Ninety-three per cent of subjects had acceptable analgesia. Seventeen mothers required more than $25 \mathrm{ml}$ to attain a T5 level: subjects having a BMI (body mass index) equai to or greater than 35, or aver 35 years of age, demonstrated more cephalad spread. Hypotension (MAP 80 per cent of control or less) occurred in 24 mothers (54 per cent), often transienty, but an infused

\section{Key words}

ANAESTHESIA; OBSTETRIC: Caesarean section; ANAESTHETICS; LOCAL: 2-chloroprocaine; COMPLICATIONS: hypotension.

From the Section of Obstetric Anesthesia, Department of Anesthesia, Bowman Gray School of Medicine of Wake Forest University, Winston-Salem, North Carolina, 27103

Address correspondence to: Dr. W.D.R. Writer, Department of Anaesthesia, Dalhousie University, Halifax, Nova Scotia, B3H 2 Y9.

Presented in part at the Annual Meeting of the Canadian Anaesthetists' Society, Halifax, Nova Scotia, Junc $13-17,1981$. fuid volume exceeding $30 \mathrm{ml} \cdot \mathrm{kg}^{-1}$ at delivery significamly reduced post-delivery hypotension. Nausea and vomiting accompanied the hypotension in 12 mothers. No neonatal depression occurred.

We conclude the incremertal administration of chloroprocaine, as described, permits safe administration of the drug, with excellent analgesia in most partarients.

In an earlier study, James et al.' demonstrated that 2-chloroprocaine compared favourably with bupivacaine for regional anaesthesia in elective Caesarean section. Subjects required $23 \pm 2 \mathrm{ml}$ chloroprocaine, three per cent, to secure initial analgesia to T4-T6, in contrast to the volume reported by Datta et al., ${ }^{2} 16 \pm 1 \mathrm{ml}$. In both studies, chloroprocaine provided more rapid onset and recovery of anaesthesia, and comparable foctal outcome. However, James found that chloroprocaine caused hypotension in 33 per cent of mothers.

Thirteen per cent of parturients in James's study required nitrous oxide inhalation to supplement analgesia before delivery, ${ }^{\prime}$ and we questioned a need for greater induction volumes of chloroprocaine, hased on further clinical experience. We therefore refined James's technique, to give subjects an augmented induction dose (minimum 25 $\mathrm{ml}$ ). In addition, we gave intraoperative increments at 40-minute intervals, because chloroprocaine's rapid hydrolysis by plasma cholinesterase leads to regression of anaesthesia in 40-50 minutes. ${ }^{3.4}$ Since Grundy et al. ${ }^{5}$ have demonstrated that even large increases in the volume of epidural anaesthetic result in only a small amount of additional spread, we were interested to learn if we could recommend 
this augmented minimum induction dose in all subjects, irrespective of stature, without unacceptably increasing matemal or foetal side effects. In addition, the use of a predetermined initial volume provided an opportunity to asscss the possible influence of a number of parameters on the analgesia level from chloroprocaine; in particular we wondered if body mass index would affect the height of block, as previously described for bupivacaine. ${ }^{6}$

The safe use of chloroprocaine requires careful steps to exclude intrathecal, or intravascular, placement of the epidural cannula, and administration of local anaesthetic in fractional doses is recommended. $^{7,8}$ We therefore devised our technique to combine safe administration, incremental doses and early confirmation of bilateral anaesthesia.

\section{Methods}

The Clinical Research Practices Committee approved the protocol and parturients gave informed consent. We studied 44 consecutive ASA physical status 1 or 2 mothers scheduled for primary or repeat elective Caesarean section. Control values of pulse and blood pressure were recorded and we then infused a 'preload' of lactated Ringer's solution, $1000 \mathrm{ml}$. With each subject in the lateral position, the epidural space was identified at a suitable lumbar level and an epidural cannula advanced up to $5 \mathrm{~cm}$. Subjects then received a test dose of chloroprocaine, $2 \mathrm{ml}$, to exclude accidental subarachnoid injection. After five minutes, and confirmation of no lower limb anaesthesia, we gave an additional $5 \mathrm{ml}$, while asking about tinnitus, circumoral numbness and rongue paraesthesiae to exclude intravascsular administration.

In the absence of symptoms, we then injected a further $3 \mathrm{ml}$, for a total of $10 \mathrm{ml}$, and waited ten minutes before assessing the response to light pinprick to confirm equal bilateral analgesia. Parturients with bilateral anaesthesia then received chloroprocaine, $15 \mathrm{ml}$-the "therapeutic" dose - for a total of $25 \mathrm{ml}$.

The fractional dose regime allowed early recognition of asymmetrical anaesthesia. If this was the case, a $5 \mathrm{ml}$ increment was given, after withdrawing the epidural cannula $1-2 \mathrm{~cm}$, to improve the symmetry of blockade. These mothers then received chloroprocaine, $10 \mathrm{ml}$ (total $25 \mathrm{ml}$ ). Each patient was supine in $15^{\circ}$ of lateral tilt until delivery.
All subjects were observed for ten minutes following the last dose, to allow upward migration of analgesia before plotting dermatome levels. If the sensory level remained below $\mathrm{T} 5$, we gave one increment of $5 \mathrm{ml}$ and waited ten minutes, or until attainment of $\mathrm{T} 5$. If the analgesia level then persisted below $\mathrm{T5}$, subjects received chloroprocaine, $5 \mathrm{ml}$, every five minutes, as needed, to secure a $T 5$ sensory level. We repeated chloroprocaine, 10 $\mathrm{ml}$, every 40 minutes, for the duration of the surgery.

Blood pressure and pulse rate were measured at two minute intervals throughout the procedure and we infused lactated Ringer's solution, as necessary, to minimise hypotension. Any drop in blood pressure, which failed to respond rapidly to an increased rate of intravenous (IV) fluid and augmented tilt, was treated with IV ephedrine, $10 \mathrm{mg}$, as required. We defined hypotension as a fall in mean arterial pressure below 80 per cent of control value at any measurement.

Using a simple three point scale to evaluate wound analgesia (Table I), a pain relief score was assigned for three intraoperative periods: skin incision to newborn delivery; delivery to abdominal closure; abdominal closure to end of surgery. Complete analgesia throughout scored nine. When determining the pain relief score, substernal discomfort and shoulder tip or suprascapular pain ( $\mathrm{C} 4$ dermatome) were excluded.

A paediatrician recorded Apgar scores at one and five minutes after delivery and umbilical vein and artery blood were withdrawn from a doubleclamped segment of umbilical cord for immediate blood gas analysis. After delivery all mothers received oxytocin infusion (20 units per $1000 \mathrm{ml}$ ).

We recorded age (yr), height (cm), weight $(\mathrm{kg})$, abdominal girth (cm), spinal length (cm) and body mass index: (weight $(\mathrm{kg}) /$ height $\left(\mathrm{m}^{2}\right)$, in all subjects.

Statistical analysis was performed using analysis of variance or Chi-square. $\mathrm{p}<0.05$ was considered significant.

\section{TABLE I Pain relief score}

No discomfort

Minimal discomfort (Pressure: No Pain)

Significant discomfort (Pain, Autonomic Symptoms) 
TABLE II Results - Analgesia $(\mathrm{N}=44)$

\begin{tabular}{llll}
\hline & & $\begin{array}{l}\text { Delivery to } \\
\text { Incision to } \\
\text { delivery }\end{array}$ & $\begin{array}{l}\text { Abdominal } \\
\text { closure } \\
\text { to skin } \\
\text { closure }\end{array}$ \\
\hline $\begin{array}{l}\text { Percentage achieving: } \\
\text { Excellent analgesia }\end{array}$ & 89 & 84 & 89 \\
Good analgesia & 7 & 11 & 9 \\
Poor analgesia & 4 & 5 & 2 \\
\hline
\end{tabular}

\section{Results}

All mothers had satisfactory regional blockade, and in no patient was it necessary to supplement analgesia with intravenous narcotics, or to proceed to general anaesthesia. In thirty-seven subjects ( 84 per cent) we described operative analgesia as excellent (pain score $=9$ ). One subject had good analgesia (pain score $=8$ ). Three mothers (seven per cent) required brief periods of nitrous oxide supplementation ( $30-40$ per cent) during the procedure, despite pin-prick analgesia to $\mathrm{T} 4$ or higher. These were also classified as good analgesia. Three mothers experienced more discomfort and required nitrous oxide inhalation for longer periods despite analgesia levels above T5. Discomfort was most common between delivery and abdominal closure (Table II) in association with uterine eventration, tubal ligation or vigorous stimulation of the parietal peritoneum, and occurred irrespective of the height of block.

Twenty-seven parturients ( 61 per cent) attained a T5 or higher level (mode T2) ten minutes after the initial $25 \mathrm{ml}$. Little further cephalad drift $(1 \pm 0.2$ segments) occurred. We observed no extension of block after each 40 -minute increment. Twelve mothers required chloroprocaine, $30 \mathrm{ml}$, to establish anaesthesia, and the five remaining subjects up to $50 \mathrm{ml}$ (mean $29 \pm 1 \mathrm{ml}$ ).

Rapid recovery of motor and sensory function followed the last dose of chloroprocaine, $64 \pm 3$ min and $68 \pm 3$ min respectively.

Before delivery, 24 parturients (54 per cent) became hypotensive, although in 17 the fall was transient and responded rapidly to treatment. Eighteen of the 24 received IV ephedrine. Twenty-one mothers were hypotensive following delivery, 11 transiently. Eleven required ephedrine. Twelve subjects experienced nausea or vomiting, which correlated significantly with hypotension $(\mathrm{p}<$
0.05 ), but not ephedrine administration. Seven mothers ( 16 per cent) had mild shortness of breath or nasal stuffiness. Following delivery, six parturients experienced substernal discomfort, statistically unrelated to uterine exteriorization, nausea or hypotension.

One newborn, whose mother became hypotensive, scored Apgar 6 at one minute and eight at five minutes. The remaining infants scored seven or more at one minute and eight or greater at five minutes. All umbilical cord blood gases were normal, and there were no significant differences between neonates from normotensive and hypotensive mothers.

In mothers with excellent analgesia, the segmental level ten minutes after the therapeutic dose, and at its maximum height, correlated with body mass index (BMI). Subjects with a BMI equal to or greater than 35 demonstrated higher block (Table III). We found a similar, but less marked, trend with age, mothers above 35 years experiencing higher segmental levels. There was no association between other parameters and the height of hlock.

\section{Discussion}

James's previous study, ${ }^{1}$ like that of Datta et al., ${ }^{2}$ confirmed the effectiveness of the surgical analgesia provided by 2-chloroprocaine in women undergoing elective Caesarean section. When compared with bupivacaine, 0.5 per cent, it provided comparable sensory block, but more rapid in onset with a latency of $14 \pm 1 \mathrm{~min}$. However, with both drugs, supplementary nitrous oxide analgesia was necessary before delivery in some cases.

Intraoperative discomfort may accompany regional techniques for Caesarean section due to maternal anxiety, peritoneal or visceral stimulation, inadequate levels of anaesthesia or poor sacral blockade. ${ }^{9-13}$ Several workers report a need for supplementary analgesia in 12-21 per cent of women to alleviate their discomfort. $9,10,12,13$ Nitrous oxide inhalation ( $25-40$ per cent), intravenous narcotic or diazepam, or low-dose ketamine have been used..$^{9,10,12,13}$ Thorburn et al. ${ }^{13}$ achieved 98 per cent acceptable analgesia by using gravity to improve sacral blockade and giving intraoperative nitrous oxide (25 per cent). We achieved excellent or good analgesia in 93 per cent of mothers, without postural change, intravenous narcotic or general anaesthesia. Although we reduced the need for 
TABLE III Spread of sensory loss in relation to BMI

\begin{tabular}{|c|c|c|c|c|c|c|c|c|c|}
\hline \multirow[b]{2}{*}{$N$} & \multirow[b]{2}{*}{$B M I$} & \multicolumn{7}{|c|}{ Cumulative percentoge attaining segmental rise } & \multirow[b]{2}{*}{ Segmen's rise } \\
\hline & & 6 & $6-7$ & $8-9$ & $I 0-1]$ & $12-13$ & $14-15$ & 16 & \\
\hline 7 & 25 & 100 & 86 & 57 & 29 & 29 & 0 & 0 & \\
\hline 12 & $25-29$ & 100 & 100 & 92 & 92 & 83 & 25 & 17 & 10 \\
\hline 14 & $30-34$ & 100 & 100 & 79 & 57 & 50 & 21 & 7 & Mins. \\
\hline 4 & $\geqslant 35$ & 100 & 100 & 100 & 100 & 75 & 25 & 0 & \\
\hline 7 & 25 & 100 & 86 & 57 & 29 & 29 & 14 & 14 & \\
\hline 12 & $25-29$ & 100 & 100 & 92 & 92 & 83 & 50 & 17 & $\operatorname{Max}$. \\
\hline 14 & $30-34$ & 100 & 93 & 86 & 64 & 64 & 50 & 14 & \\
\hline 4 & $\geqslant 35$ & 100 & 100 & 100 & 100 & 100 & 75 & 25 & \\
\hline
\end{tabular}

$N=37$

After Hodgkinson R et al ${ }^{\sigma}$

supplementary analgesia before delivery from 13 per cent to 7 per cent, perhaps because of the augmented initial dose and higher segmental level, intraoperative pain still occurred, especially between delivery and abdominal closure, necessitating nitrous oxide supplementation in 14 per cent of mothers overall. Uterine eventration was invariably employed by the obstetrician, probably accounting for this discomfort.

The height of block, ${ }^{12}$ the local anaesthetic agent, ${ }^{1,2}$ and the criteria used to define intraoperative hypotension determine its incidence. ${ }^{1,2,12,13}$ Although James' previously defined hypotension as the need for ephedrine, we administered the drug more aggressively in this study, precluding that definition. Since regional anaesthesia reduces diastolic blood pressure first, such that mean arterial pressure depends on the level of segmental blockade, ${ }^{4}$ we felt it more appropriate to define hypotension by the fall in mean pressure. However, our stringent criteria may have increased its apparent incidence. In 35 per cent of our mothers, systolic pressure fell by $30 \mathrm{mmHg}$, or to less than 100 $\mathrm{mmHg}$, the criteria used by Datta et al., ${ }^{2}$ and an incidence which compares with James's previous findings. ${ }^{\prime}$ In contrast, Wright et al. ${ }^{14}$ reported 60 per cent hypotension (systolic pressure below 100 $\mathrm{mmHg}$ ) after chloroprocaine, while the incidence following subarachnoid block is 80 per cent in some studies. ${ }^{11}$ James et al. ${ }^{15}$ suggest it may be inappropriate to label systolic pressures below $100 \mathrm{mmHg}$ hypotensive, since they occur commonly in preoperative term pregnant mothers without deleterious maternal or foetal effects. The normal Apgar scores and umbilical cord blood gases in this study suggest a lack of neonatal depression from the frequently transient hypotension.

Although hypotension may reflect the height of block (T2) in our series, the rapid onset of epidural chloroprocaine, resembling subarachnoid block, limited the fluid volume given before delivery, and may have accentuated the fall in pressure. However, the volume of crystalloid our subjects received did not influence the incidence or magnitude of pre-delivery hypotension. In contrast, mothers who became hypotensive after delivery received significantly less lactated Ringer's solution $(30 \pm 2$ $\mathrm{ml} \cdot \mathrm{kg}^{-1}$ ) than mothers who remained normorensive ( $37 \pm 2 \mathrm{ml} \cdot \mathrm{kg}^{-1}$ ). The incidence of post-delivery hypotension fell from 70 to 37 per cent, if mothers had more than $30 \mathrm{ml} \cdot \mathrm{kg}^{-1}$ Ringer's lactate by the delivery time (Table IV). Gibbs et al. ${ }^{16}$ also found intraoperative hypotension less frequent and less

TABLE IV Post-delivery hypotension ( $\mathrm{N}=44$ )

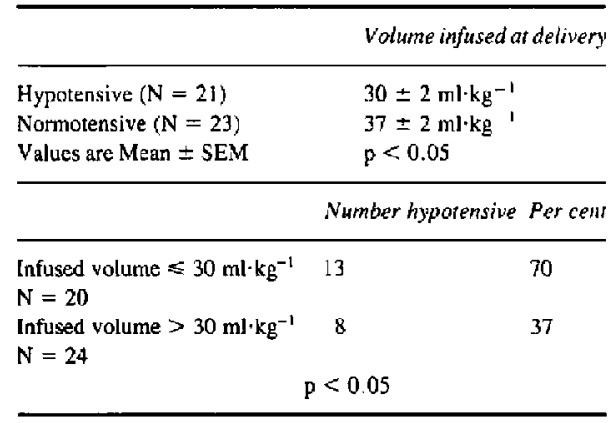


severe in their subjects having Ringer's lactate 30 $\mathrm{ml} \cdot \mathrm{kg}^{-1}$ for pre-hydration in Caesarean section.

Our incidence of nausea and vomiting exceeds that reported in Thorburn's study of bupivacaine. ${ }^{13}$ Datta et al. ${ }^{17}$ demonstrated significantly less nausea and vomiting following prompt administration of IV ephedrine, as soon as any fall from baseline pressure was detected during spinal anacsthesia. Since we found a positive correlation of these symptoms with hypotension, it perhaps suggests a need for more immediate use of ephedrine than we employed.

The short duration and abrupt termination of chloroprocaine's effect necessitate increments at appropriate intervals. Bromage ${ }^{4}$ reported twosegment recession of block in $57 \pm 7$ minutes (40-65 minutes) and advocated re-injection after 47 minutes. The lack of cephalad spread after the 40-minute increments in our subjects confirms our choice of the correct dosing interval, and reflects the experience of Datta et al. ${ }^{2}$

Hodgkinson et al. ${ }^{6}$ observed higher levels of block in obese patients receiving bupivacaine 0.75 per cent for Caesarean section. Increasing maternal age also correlated with higher levels in their subjects. Although we found no absolute correlation between BMI and anaesthetic level, our findings confirm these trends with chloroprocaine and emphasize the need for caution in these subjects to avoid unacceptably high blocks.

Following reports of prolonged sensory/motor deficit, which appeared to be related to accidental intrathecal injection of chloroprocaine, Covino et al. ${ }^{7}$ prepared guidelines for the drug's safe administration. These guidelines recommended careful testing to rule out inadvertent intrathecal (or intravascular) placement of the "extradural" catheter with a test dose of $3 \mathrm{ml}$ of chloroprocaine, three per cent. Although we administered $2 \mathrm{ml}$ initially, we waited five minutes to allow any symptoms of spinal anaesthesia to develop. Since we then gave two further doses, $5 \mathrm{ml}$ and $3 \mathrm{ml}$, and waited another ten minutes before augmenting anaesthesia, an inadvertent subarachnoid dose, overlooked after the initial $2 \mathrm{ml}$, would have become evident after these fractional doses and permitted removal of CSF, $10 \mathrm{ml}$, if necessary ${ }^{8}$ Our 'therapeutic' dose, maximum $15 \mathrm{ml}$, although larger than recommended, only followed after we confirmed bilateral analgesia to an appropriate and expected height, from the initial $10 \mathrm{ml}-\mathrm{T} 11$ in our subjects (range T7-L2). No mother sustained an accidental dural puncture or prolonged block.

We consider our augmented induction dose and incremental technique permits safe administration of chloroprocaine, three per cent, and offers excellent analgesia to most parturients having electivc Caesarean section. Although hypotension accompanies the rapid onset of blockade, a pre-delivery fluid load exceeding $30 \mathrm{ml} \cdot \mathrm{kg}^{-1}$ may be expected to minimise it, especially after delivery. More cephalad spread of anaesthesia may be anticipated when BMI and age exceed 35 .

\section{References}

I James FM, Dewan DM, Floyd HM, et al. Chloroprocaine us. bupivacaine for lumbar epidural analgesia for elective cesarcan section. Anesthesiology 1980; 52: 488-91.

2 Datta $S$, Corke BC, Alper MH, Brown WU Jr, Ostheimer $G W$, Weiss $J B$. Epidural anaesthesia for cesarean section: a comparison of bupivacaine, chloroprocaine, and etidocaine. Anesthesiology 1980; 52:48-51

3 Finster $M$, Pedersen $H$. Placental transfer and fetal uptake of drugs. Br J Anaesth 1979; 5I: 25s-28s.

4 Bromage PR. Epidural analgesia. Philadelphia: Suunders, 1978.

5 Grundy EM, Ramamurthy S, Parel KP, Mari M. Winnie AP. Extradural analgesia revisited: a statistical study. Br J Anaesth 1978; 50: 805-9.

6 Hodgkinson R. Husain FJ. The relationship between obesity, age and other factors and the highest level of sensory loss following the epidural administration of a standard dose of bupivacaine. Abstracts 1] th Annual Meeting of the Society for Obstetric Anesthesia and Perinatology, Winston-Salem, 1979. p. 24.

7 Covino BG, Marx GF. Finster $M$, Zsigmond EK. Prolonged sensory/motor deficits following inadvcrtent spinal anesthesia (Editorial). Anesth Analg 1980; 59: 399-400.

8 Covino BG. Potential neurotoxicity of local anaesthetic agents. Can Anaesth Soc J (Editorial). 1983; 30: 111-6.

9 Milne MK, Murray Lawson $\boldsymbol{H}$. Epidural analgesia for caesarean section. Br J Anaesth 1973; 45: 1206- 10 .

10 Shnider $S M$, Levinson $G$. Anesthesia for cesarean section. In: Shnider SM, Levinson G, eds. Ancsthe- 
sia for Obstetrics. Baltimore: Williams and Wilkins, 1979: 254-75.

11 Datta S. Alper MH. Ancsthesia for ccsarcan section. Anesthesiology 1980; 53: 142-60.

12 Craft JB Jr, Roizen MF, Dao SD, Edwards $M$, Gilman R. A comparison of T4 and T7 dermatomal levels of analgesia for caesarean section using the lumbar epidural technique. Can Anaesth Soc J 1982; 29: 264-9.

13 Thorburn J, Moir DD. Epidural analgesia for elective caesarean section. Technique and its assessment. Anaesthesia 1980; 35: 3-6.

14 Wright RG. Shnider SM, Levinson G, et al. Maternal and fetal plasma norepinephrine levels during cpidural ancsthesia for clective section. Abstracts of Scientific Papers, Annual Meeting American Society of Anesthesiologists, Chicago, 1978, 109-110.

15 James $C F$, Gibbs $C P$, Gravenstein JS, If J van der $A$. Maternal hypotension: are current criteria valid? Anesthesiology 1982; 57: A 393.

16 Gibbs CP, Spohr L, Petrakis J, Paulus D, Schultetus $R$. Prevention of hypotension with hydration. Anesthesiology 1981; 55: A 308.

17 Datta S, Alper MH, Ostheimer GW, Weiss JB. Method of ephedrine administration and nausea and hypotension during spinal anesthesia for cesarean section. Anesthesiology 1982; 56: 68-70.

\section{Résumé}

Nows avons évalué la 2-chlorprocaine à trois pour cent en injection péridurale chez 44 patientes au cours de l'opération césarienne. Chaucune a reçu une dose minimum de $25 \mathrm{ml}(750 \mathrm{mg})$ en injections fractionnés permettant de reconnaître de façon précoce toute injection intravasculaire ou sous-arachnoidieme de l'agent anesthésique. Des doses complémentaires ont été administrées afin de parvenir à un niveau d'aneshlésie attei. grant DS on plus haut. Le pouls et la pression artérielle ont été enregistrés aux deux minutes et la qualité de l'anal. gésie évaluée surr une échelle algométrique.

L'analgésie a élé adéquate chez 93 pour cent des patientes, 17 d'entre elles on nécessité pirs de $25 \mathrm{ml}$ pour obterir une anesthésie à 05. On a observé une diffusion céphalade plus marquée chez les patientes à index de musse corporelle de 35 ou plus et chez celles âgées de 35 ans et plus. Vingt-quatre patientes (54 pour cent) ont présenté un certain degré d' hypotension (pres. sion artérielle moyenne 80 pour cent de la valeur contröle ou moins), hypotension sowent transitoire. L'hypotension qui suivait la délivrance a été sensiblenrent réduite par l'administration de liquide dans lordre de 30 $\mathrm{ml} / \mathrm{kg}^{-1}$. Chez 12 patientes cette iypotension s'est accompagnée de nausées et de vomissements. On n'a observé auccune dépression du nouveau-né.

On en conclut que l'administration en doses fractionnées de chlorprocaine telles que décrites consritue une façon siure d"administrer le médicament et d'assurer une excellente analgésie chez la plupart des patientes. 